\title{
DIFERENCIAÇÃO DE MAGMAS GRANITICOS EM ZONAS DE CISALHAMENTO: O CASO DE TAUÁ, CEARÁ
}

\author{
SÉRGIO PACHECO NEVES*
}

\begin{abstract}
DIFFERENTIATION OF GRANITIC MAGMAS IN SHEAR ZONES: THE TAUÁ CASE, CEARÁ Sheets of granitoid rocks were intruded in the central segment of the Taua Shear Zone, a major transcurrent shear zone of the Ceara State. These rocks exhibit a compositional range from quartz-monzodiorite to granodiorite or granite, becoming progressively richer in felsic minerals from south to north. A petrographic study of microdioritic enclaves, present in the more mafic members and interpreted as cognate cumulates, is used to disregard a magma mixing or restite-unmixing origin for these rocks. A well defined flow foliation and the presence of hornblenditic bands indicate that the petrographic variation must result from fractionation of hornblend through the mechanism of flow differentiation. The parallelism between the igneous hornblend crystals and the sub-horizontal lineation in the deformed wall rocks is taken as evidence that melt transport was paralel to the displacement of the country rocks. A model is then proposed where the subvertical foliation in the shear zone facilitated the ascent of magmas which were in turn induced to flow horizontally at the intrusion level.
\end{abstract}

RESUMO No segmento central da Zona de Cisalhamento Tauá, uma das maiores transcorrências dúcteis do Estado do Ceará, são encontrados vários corpos concordantes e alongados de granitóides. Essas rochas exibem uma variação composicional de quartzo-monzodiorítica a granodiorítica ou granítica, tornando-se progressivamente mais ricas em minerais félsicos de sul para norte. Um estudo petrográfico dos encraves microdioríticos presentes nos membros mais máficos, interpretados como cumulados cognatos, é usado para descartar uma origem para essas rochas pela mistura de magmas ou da separação de restitos e líquidos graníticos. Uma foliação de fluxo bem definida e a presença de bandas hornblendíticas indicam que a variação petrográfica deve resultar do fracionamento de hornblenda pelo mecanismo de diferenciação por fluxo. O paralelismo entre os cristais de hornblenda e a lineação de estiramento sub-horizontal nas encaixantes é tomado como evidência de que o transporte do magma foi paralelo ao deslocamento das rochas regionais. Propóe-se então um modelo em que a foliação subvertical na zona de cisalhamento induziu a ascensão de magmas que foram subseqüentemente forçados a fluir horizontalmente no nível de intrusão.

INTRODUÇÃo No segmento central da Zona de Cisalhamento Tauá, Ceará (Fig. 1), são encontrados vários corpos alongados de granitóides, dispostos paralela ou subparalelamente aos contatos com as rochas encaixantes (Fig. 2). Com base em critérios petrográficos, esses granitóides podem ser divididos em dois tipos: o primeiro consiste em granitóides relativamente grossos e composicionalmente variados, correspondendo ao Ortognaisse de Cratéus, de Tagliani \& Gomes (1988) e Tagliani et. al. (1988), e o segundo de granitos (sensu strictu) de granulação fina e compostos quase exclusivamente por quartzo, microclínio e plagioclásio sódico.

A presença ocasional de pequenos xenólitos do granito grosso no fino e de diques de granito fino cortando o grosso (Foto 1) indica o caráter tardio dos granitos do segundo tipo. As composições modais desses últimos plotam próximas ao mínimo de fusão para baixas pressões de água no sistema $\mathrm{Ab}-\mathrm{Or}-\mathrm{Qz}-\mathrm{H}_{2} \mathrm{O}$ e isto, juntamente com a granulação fina, sugere cristalização em níveis crustais relativamente rasos. Esses granitos não serão mais abordados no decorrer do trabalho.

Os granitóides do primeiro tipo, apesar dos efeitos deformacionais superimpostos, preservam muitas feições primárias e por isso o termo ortognaisse parece impróprio, como se discutirá adiante. Eles serão referidos como granitos Pedra Lisa (a localidade de mais fácil acesso, onde excelentes afloramentos podem ser encontrados. Ver Fig. 2). O propósito deste estudo é avaliar qual (ou quais) o(s) processo(s) responsável(is) pelas variações composicionais apresentadas por essas rochas e qual o controle exercido pela deformação na zona de cisalhamento sobre esse(s) processo(s).

A ZONA DE CISALHAMENTO TAUÁ A "Falha" de Tauá foi reconhecida por Arthaud (1986) como uma zona de cisalhamento dúctil, transcorrente, com rejeito sinistral. Essa transcorrência é uma das mais extensas entre aquelas que

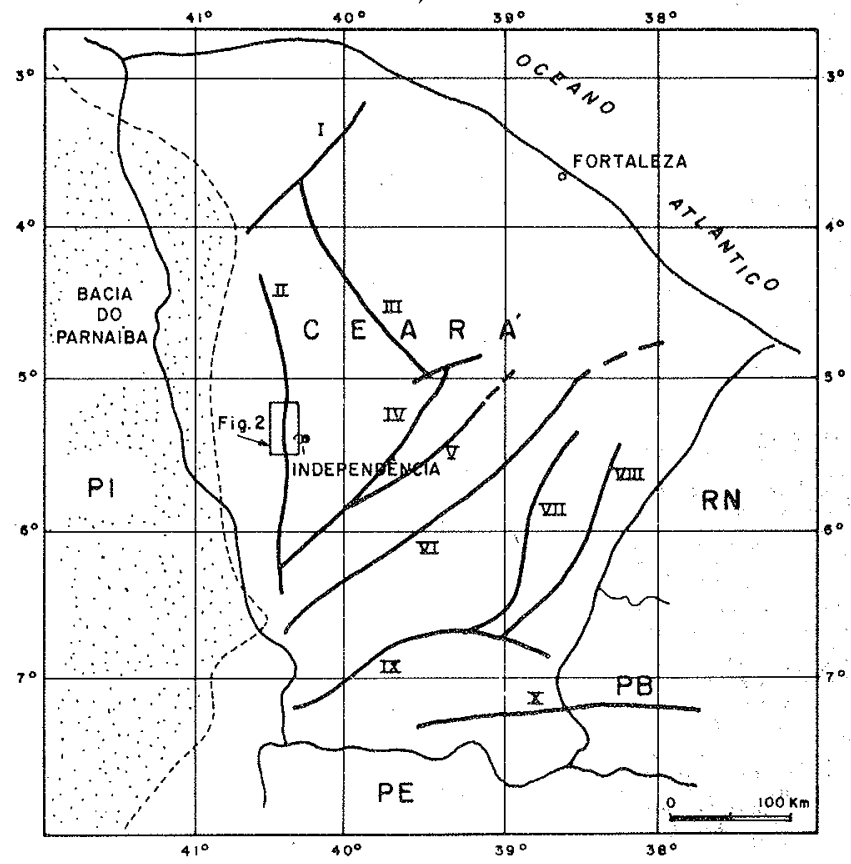

Figura 1 - As principais zonas de cisalhamento transcorrentes do Estado do Ceará: I. Sobral-Pedro II; II. Tauá; III. Rio Groairas; IV. Sabonete-Inharé; V. Quixeramobim; VI. Senador Pompeu; VII. Orós; VIIL. Rio Jaguaribe; IX. Tatajuba; X. Patos

Figure 1 - The major transcurrent shear zones of the Ceara State: $\mathbf{I}$. Sobral-Pedro II; II. Tauá; III. Rio Groairas; IV. Sabonete-Inhare; V. Quixeramobim; VI. Senador Pompeu; VII. Órós; VIII. Rio Jaguaribe; IX. Tatajuba; X. Patos

* Universidade Federal de Pernambuco, Centro de Tecnologia, Departamento de Geologia, Rua Acadêmico Hélio Ramos, s/nō, CEP 50741, Recife, PE 


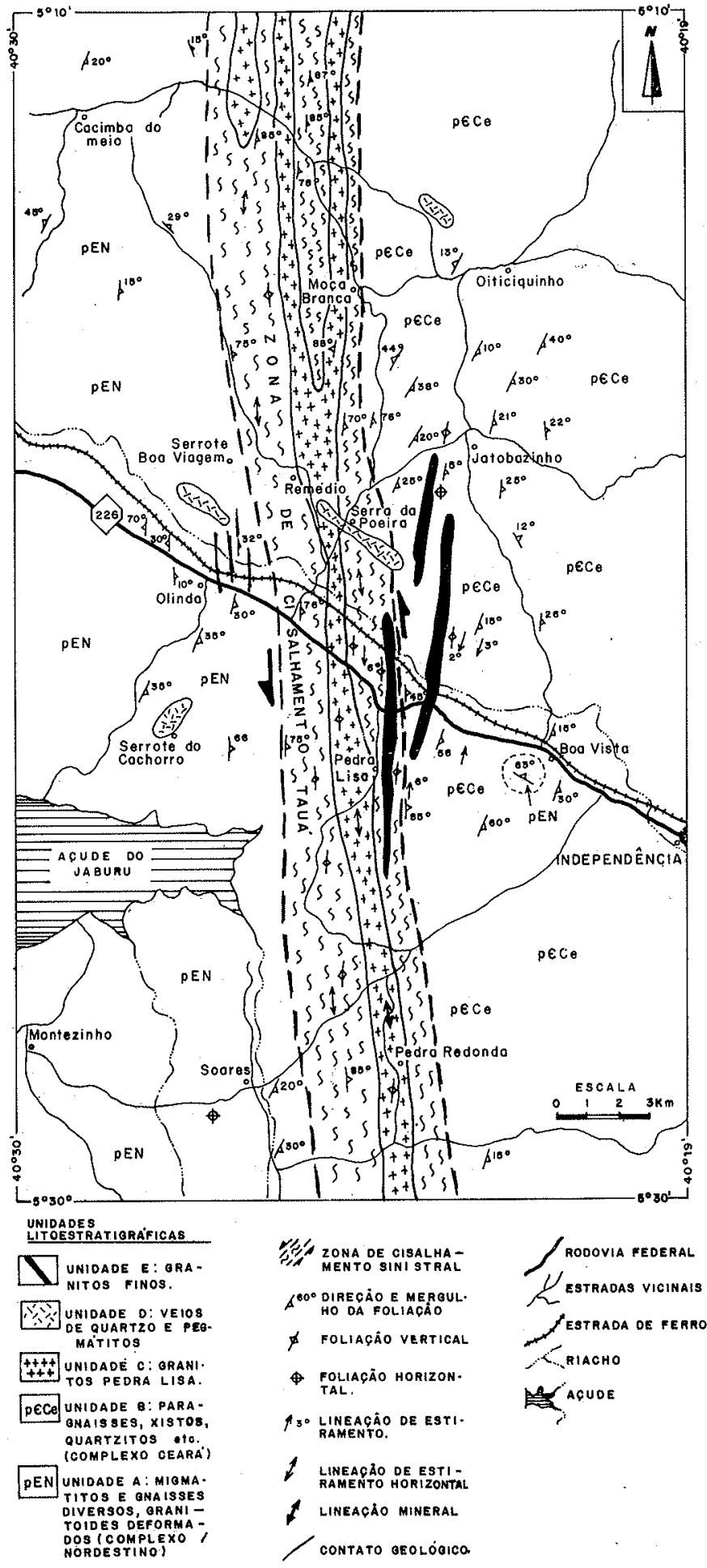

Figura 2 - Mapa geológico simplificado da porção oeste da Folha de Independência (CE)

Figure.2 - Simplified geological map of the western portion of the Independência Sheet

recortam o pré-cambriano do Estado do Ceará (Fig. 1) e, na area mapeada, tem de 3 a $4 \mathrm{~km}$ de largura. Embora a deformação mais intensa esteja concentrada na faixa assinalada na figura 2 , os efeitos do cisalhamento podem ser sentidos, a partir da linha mediana desta faixa, por uma distância de mais de $5 \mathrm{~km}$, tanto para leste como para oeste. Esses efeitos são registrados ora por uma forte lineação de estiramento subhorizontal de direção aproximada $\mathrm{N}-\mathrm{S}$, ora por faixas miloníticas subverticais que recortam uma foliação oblíqua de mais

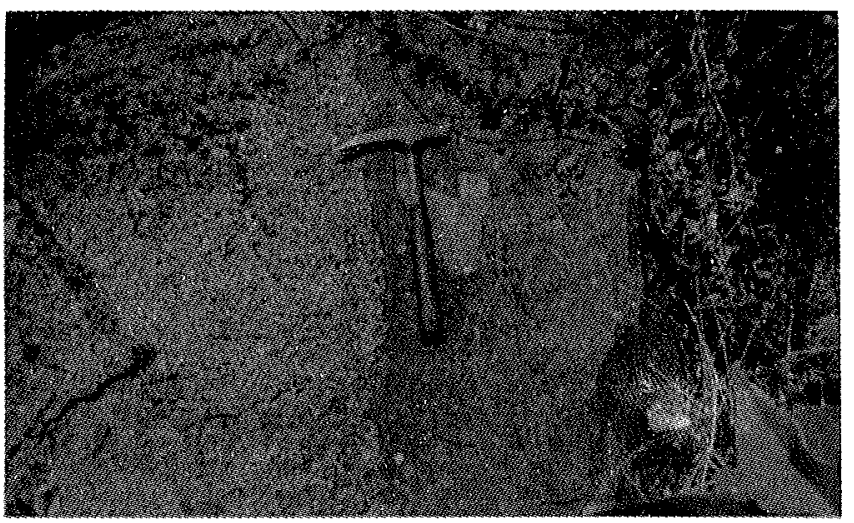

Foto 1 - Dique de granito fino truncando granito grosso foliado (tipo Pedra Lisa)

Photo 1 - Dike of fine-grained granite cross-cutting foliated coarsegrained granite (Pedra Lisa type)

baixo ângulo. $\mathrm{O}$ caráter heterogêneo da deformação é atestado pela presença de pods, mesmo na região mais deformada, e pela variação na intensidade de milonitização, podendo os litotipos pre-existentes apresentar gradações de protomilonitos até ultramilonitos.

$\mathrm{Na}$ área estudada, a Zona de Cisalhamento Tauá separa duas unidades geologicamente distintas. A leste são encontrados paragnaisses diversos, xistos, quartzitos, mármores e rochas cálcio-silicáticas de possível idade brasiliana, agrupados por Arthaud et al. (1988) no Complexo Ceará, e a oeste migmatitos e gnaisses diversos de idade proterozóica inferior ou arqueana, pertencentes ao Complexo Nordestino (Gomes et al. 1981). No interior da zona de cisalhamento estão presentes os equivalentes milonitizados das rochas dessas duas unidades juntamente com as rochas graníticas em análise (Fig. 2).

A foliação nas encaixantes, tanto a leste como a oeste, tem direçóes variando de $\mathrm{N}$ a NNE e mergulhos de moderados a baixos (geralmente menores que $45^{\circ}$ ) para E-ESE. O ângulo de mergulho aumenta em direção à zona de cisalhamento, mas não de maneira sistemática. A foliação no interior da zona é subparalela aos limites desta e caracterizada por mergulhos de alto ângulo (acima de $70^{\circ}$ e freqüentemente subverticais) e por uma lineação de estiramento sub-horizontal. Fissuras de extensão, orientadas obliquamente à direção $\mathrm{N}-\mathrm{S}$ da zona e preenchidas por quartzo ou pegmatitos, são comuns e algumas delas atingem dimensões suficientes para ser representadas em mapas (Fig. 2).

PETROGRAFIA Os granitos Pedra Lisa estão restritos ao interior da Zona de Cisalhamento Tauá e ocorrem como corpos alongados, subparalelos e interconectados, com fatias das rochas encaixantes interpostas entre eles. Isso pode ser visto na porção norte da área (Fig. 2) mas também se verifica numa escala menor, embora cada lente individual nãe possa ser representada devido a suas pequenas espessuras, que variam de algumas dezenas a umas poucas centenas de metros. Apesar de o padrão anastomosado da intrusão não poder ser apreendido a partir do mapa, o ponto importante a ressaltar é a continuidade longitudinal e a falta de truncamentos ou mesmo de contatos difusos quando duas lentes coalescem para formar corpos mais espessos, implicando que todas elas fazem parte da mesma intrusão.

O contato com as encaixantes, quando observado, é sempre feito com migmatitos do tipo estromático e não é estritamente paralelo com o bandamento migmatítico, fäzendo um pequeno ângulo com ele (Foto 2). Além disso, o contato não é brusco na escala de alguns metros, observando-se injeções graníticas ao longo dos planos de foliação das encaixantes. Isso e a existência de xenólitos de migmatito com vários metros de com- 
primento, evidenciando inclusão aproximadamente in situ, sugerem que a intrusão se deu aproveitando a foliação subverticalizada na zona de cisalhamento. Como resultado desse processo as rochas preexistentes foram desmembradas, englobadas e, possivelmente, assimiladas em parte pelo magma.

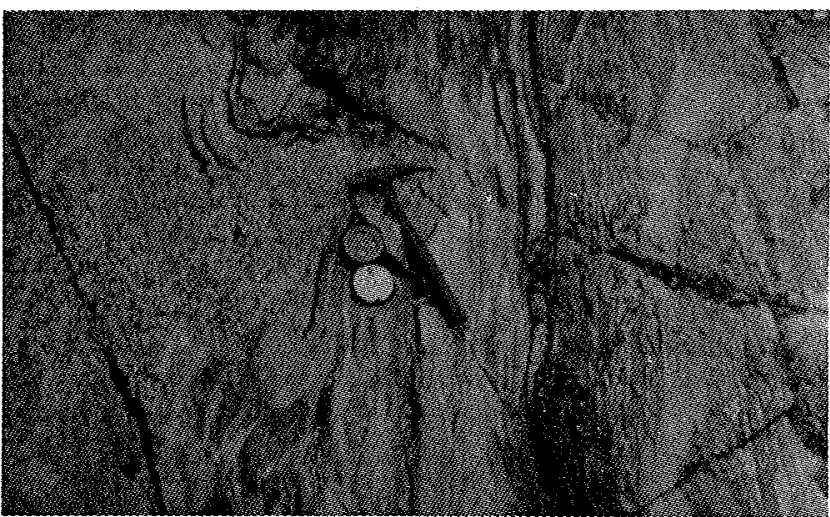

Foto 2 - Contato migmatito-granito Pedra Lisa. Notar no centro da foto o truncamento do bandamento migmatítico pelo granito e a presença de encraves microdioríticos encurvados Photo 2 - Migmatite-Pedra Lisa granite contact. Note at the center the truncation of the migmatite banding and the presence of curved microdioritic enclaves

A composição dos granitóides varia de quartzo-monzodiorítica a granodiorítica ou granítica, de sul para norte havendo um aumento progressivo nas razões quartzo/feldspatos, feldspato potássico/plagioclásio e minerais félsicos/minerais máfi cos. Nos membros mais máficos, a sul, a textura é ineqüigranular, com cristais maiores de plagioclásio e hornblenda (ou agregados de hornblenda e biotita) com atê $1,2 \mathrm{~cm}$ inseridos em uma matriz de granulação média $(2-3 \mathrm{~mm})$ composta pelos mesmos minerais, além de quartzo, microclínio e biotita. Titanita, zircão e apatita estão presentes em quantidades acessórias e só ocasionalmente fenocristais de feldspato potássico são encontrados. Para norte, a quantidade de fenocristais (com diâmetros médios de 2 a $4 \mathrm{~cm}$ ) aumenta bastante e a textura se torna marcadamente porfirítica. Embora a textura da matriz continue a mesma, sua composição agora é essencialmente granítica e empobrecida em minerais máficos. Acompanhando essas mudanças composicionais e texturais, é observado também um aumento no volume de pegmatitos de sul para norte.

A quantidade de hornblenda nos membros mais máficos freqüentemente supera $15 \%$ e é comum sua concentração em faixas quase monominerálicas com alguns centímetros de espessura (Fotos 3 e 4). Também neles é mais freqüente a presença de xenólitos (quase sempre de migmatitos e de encraves microdioríticos (Fotos 4 e 5). Estes últimos têm dimensões decimétricas e em planta apresentam formas de subelípticas (razões axiais de $3: 1$ a 5:1; Foto 4) alongadas (razões axiais acima de $15: 1$; Foto 5 ).

Em uma quantificação da deformação nos granitos Pedra Lisa, realizada por Tagliani et al. (1988) utilizando o método Fry (1979), a razão X/Z variou de 2,8 (amostras mais deformadas) a 1 (amostras não deformadas). Mesmo nas amostras pouco ou não-deformadas, uma foliação, mais ou menos bem desenvolvida, é mesoscopicamente definida por xenólitos e encraves alongados e pelas faixas hornblendíticas. Nessas amostras, microscopicamente observa-se uma orientação preferencial de cristais tabulares (euedrais a subedrais) de plagioclásio, prismas de anfibólio e palhetas de biotita. A maioria dos grãos desses minerais é praticamente livre de feições deformacionais internas mais intensas, embora muitos apresentem extinção ondulante de fraca a moderada. Mesmo quartzo,

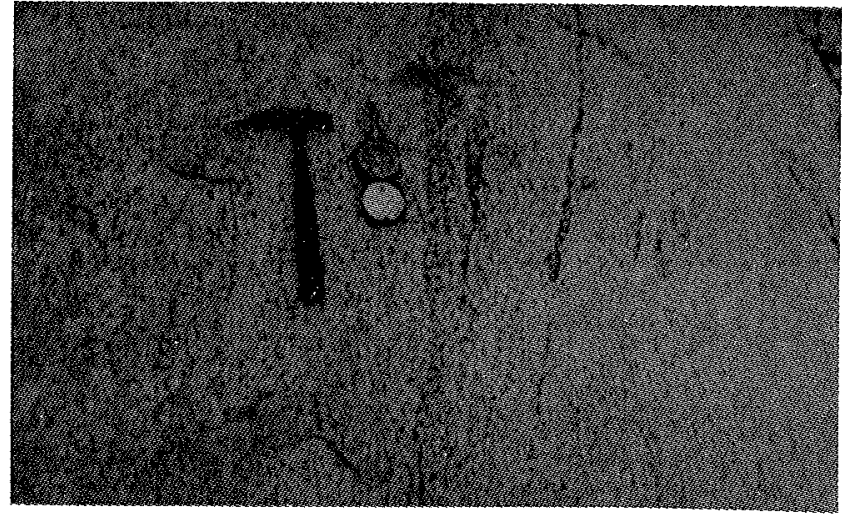

Foto 3 - Faixas escuras (centro) causadas pela concentração de cristais de hornblenda

Photo 3 - Dark bands (center) caused by concentration of hornblend crystals

que é a fase mais dúctil em rochas graníticas, não é muito deformado, ocorrendo em agregados pouco alongados exibindo apenas incipiente recristalização para subgrãos. Essas observações mostram que a foliação deve ter resultado do fluxo magmático durante a cristalização, com os cristais inicialmente formados rotacionando e assumindo uma orientação preferencial. Por analogia, a foliação nas rochas mais deformadas também deve ser em parte primária e por esse motivo o termo ortognaisse aplicado a elas parece inadequado já que, por definição, uma trama gnáissica é adquirida por deformação no estado sólido.

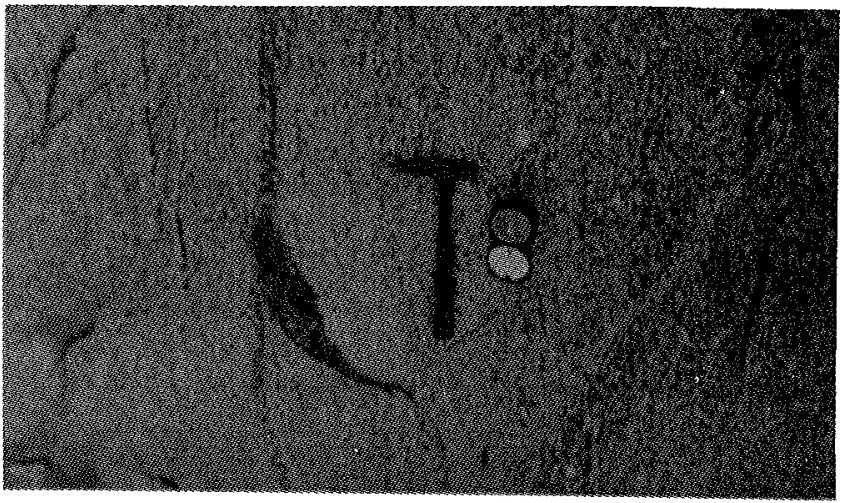

Foto 4 - Encrave microdioritico, com forma subeliptica e terminações sigmoidais, provavelmente rotacionado durante o fluxo magmático que originou a foliação primária definida pela faixa hornblendítica (porção mais escura)

Photo 4-Subeliptical shaped, sigmoidally ended, microdioritic enclave probably rotated during the magmatic flow which gave rise to the primary foliation defined by the hornblenditic band (darker portion)

Nas amostras mais deformadas, uma foliação milonítica, dada principalmente pelo estiramento e recristalização de grãos de quartzo e biotita, está superimposta à foliação primária. Os cristais maiores de feldspatos e hornblenda estão recristalizados nos bordos, gerando porfïroclastos assimétricos que foram utilizados por Tagliani \& Gomes (1988) para deduzir o caráter sinistral da transcorrência. Todos os grãos desses minerais estão deformados internamente, sendo particularmente comuns kink bands e geminados mecânicos, e transformações retromórficas acompanhantes promovem a desestabilização de hornblenda para biotita, epídoto e titanita e de plagioclásio para sericita, epídoto e calcita. Em alguns lo- 
cais, a foliação milonítica é bastante intensa e faixas ultramiloníticas chegam a se desenvolver, porém na maioria dos casos a foliação primária não é totalmente obliterada.

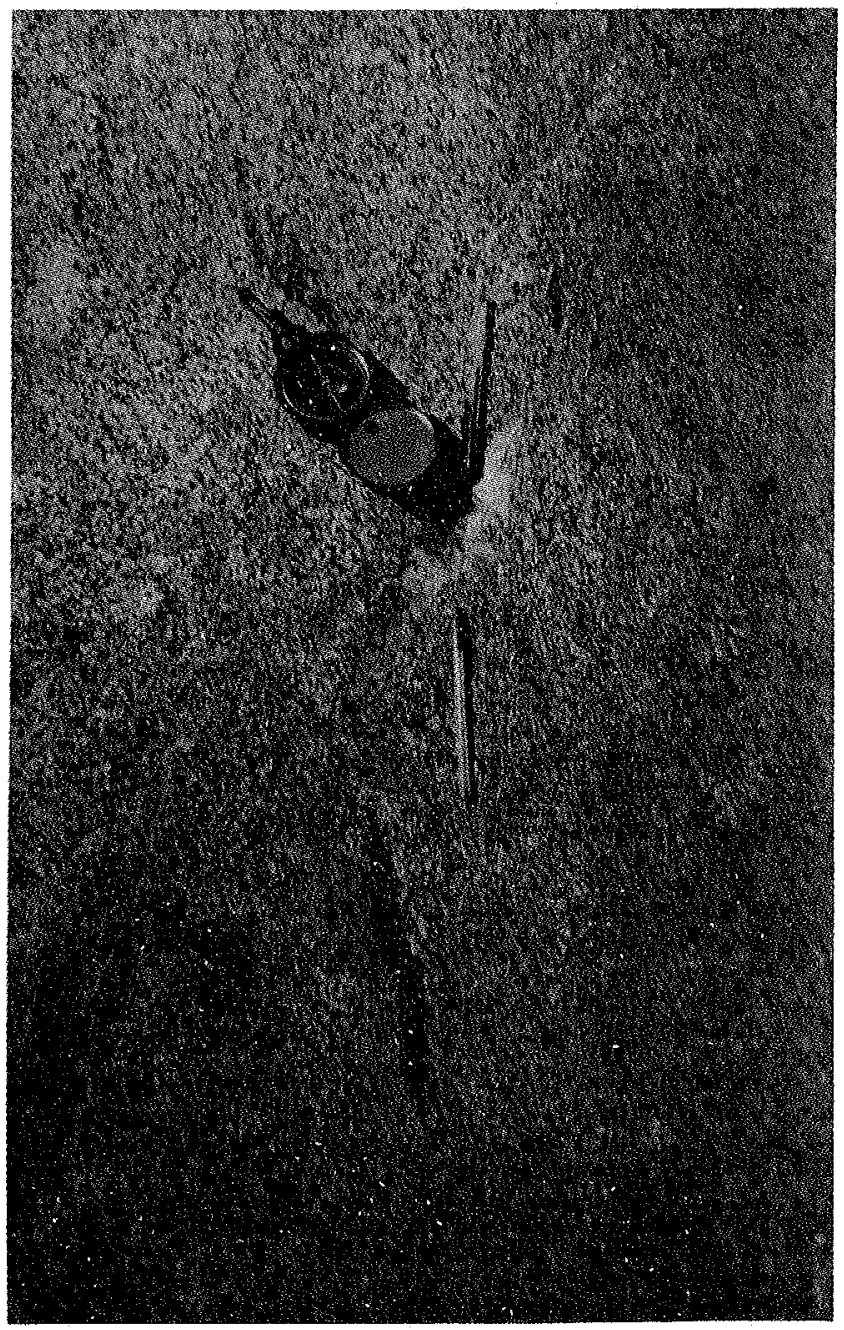

Foto 5 - Encrave microdiorítico alongado no granito Pedra Lisa. É mostrada ainda uma fissura de extensão, preenchida por quartzo, relacionada a um cisalhamento destral tardio Photo 5 - Elongate microdioritic enclave in the Pedra Lisa granite. Also shown a quartz-filled extension fissure related to a late dextral shear

A existência de porções dos granitóides pouco afetadas pela deformação indica o caráter sin-a tarditectônico da intrusão. Como a maioria dos xenólitos de migmatitos, incluindo aqueles encontrados nas amostras pouco deformadas, apresenta indícios de milonitização, isso comprova que o cisalhamento precedeu a intrusão.

MECANISMO DE DIFERENCIAÇÃO Algum mecanismo de diferenciação deve ter atuado para promover as variações composicionais encontradas de sul para norte. Apesar de a assimilação das fases minerais de mais baixa temperatura (quartzo e feldspato) das rochas encaixantes poder ser bastante efetiva, a ponto de causar um aumento de acidez em corpos com dimensões batolíticas (por exemplo, Ague \& Brimhall 1987), a eficácia desse processo está diretamente ligada ao volume dos corpos ígneos. Nos granitos Pedra Lisa, alguns encraves surmicáceos (Didier 1973, 1987) parecem resultar da fusão parcial de xenólitos de biotita gnaisse e, assim, alguma assimilação deve ter ocorrido. No entanto, em vista da peque- na dimensão dos corpos, é improvável que isso possa ter causado variações composicionais significativas.

O mecanismo clássico de diferenciação é o da cristalização fracionada (Bowen 1928). Nos últimos anos, porém, dois outros processos têm sido freqüentemente invocados para explicar variações composicionais em suítes de rochas ígneas: $i$. mistura, completa ou incompleta, de dois ou mais magmas derivados separadamente (Eichelberger 1978), e ii. desmistura, em graus variados, de líquidos graníticos contendo proporções variadas do material-fonte residual do evento de fusão parcial (o restite-unmixing model de White \& Chappell 1977). Para avaliar qual desses três processos é mais provável no caso dos granitos Pedra Lisa foi feita uma análise micropetrográfica dos encraves microdioríticos.

Os encraves microdioríticos Encraves microgranulares em granit6ides podem ser restitos da rocha-fonte (White \& Chappell 1977, Chappell et al. 1987), estruturas tipo almofada (pillows) resultantes de mistura de magmas (Didier 1987, Reid et al. 1983, Vernon 1983) ou cumulados cognatos, porções cristalizadas precocemente e reabsorvidas pelo magma (Didier 1973, Vernon 1983). Encraves surmicáceos podem ser confundidos, a vista desarmada, com essas inclusões, mas são facilmente distinguíveis ao microscópio.

A interpretação de encraves microgranulares como restitos ultimamente tem sido bastante questionada (para pontos de vista opostos, ver Chappell et al. 1987 e Wall et al. 1987). De acordo com Wall et al. (op. cit.), para uma inclusão ser identificada como restito, ela deve apresentar uma textura granoblástica e paragêneses indicativas de altas pressões e temperaturas, já que a região-fonte de granitos de derivação crustal deve ser terrenos de alto grau metamórfico e composiçóes empobrecidas em sílica e álcalis, que são consumidos durante a produção de magmas graníticos. Os encraves nos granitos Pedra Lisa apresentam uma textura ígnea e uma mineralogia magmática primária, com cristais euedrais a subedrais de plagioclásio e hornblenda, e quase sempre contêm quartzo (e, às vezes, feldspato potássico), podendo-se portanto descartar uma origem restítica para os mesmos.

A distinção entre cumulados cognatos e glóbulos produzidos por uma mistura de magmas é mais problemática porque, embora resultem de processos distintos (cumulados cognatos são englobados no estado sólido e têm uma ligação genética com suas hospedeiras) em ambos os casos uma granulação mais fina e minerais de mais alta temperatura que as hospedeiras são característicos. No entanto, nenhuma das feições consideradas mais típicas de inclusões resultantes de mistura de magmas foi identificada nos encraves dos granitos Pedra Lisa. Essas feições incluem (Didier 1987, Reid et al. 1983, Vernon 1983, Vernon et al. 1988, Wall et al. 1987): contatos crenulados e margens de esfriamento brusco (chilled margins), tomadas como evidência de que elas estavam pelo menos parcialmente no estado líquido e sofreram um rápido resfriamento ao entrar em contato com um magma mais ácido, e incorporação pelo encrave de minerais que estão cristalizando no magma granítico, o caso mais notável sendo o de fenocristais de feldspato potássico, que podem até cruzar o contato granito-encrave. Embora contatos crenulados e margens de esfriamento possam ser erodidos durante o transporte magmático, resultando em encraves mais regulares (Didier 1987), a ausência de minerais incorporados sugere que os encraves nos granitos Pedra Lisa foram englobados no estado sólido. Adicionalmente, em vários locais observam-se encraves orlados por cristais de hornblenda contrastando com a existência de auréolas leucocráticas, resultantes da difusão de $\mathrm{Si}, \mathrm{K}$ e Rb para o componente básico, encontradas em alguns encraves resultantes de mistura de magmas (Zorpi et al. 1989). Isto é indicativo da nucleação dos cristais deste mineral aproveitando uma superfície já solidificada, corroborando a interpretação dos encraves como cumulados cognatos. 
Assim, apesar de a hipótese de mistura de magmas não poder ser inteiramente descartada sem estudos químicos e isotopicos adicionais, $\epsilon$ mais provável que os encraves representem porções cristalizadas precocemente ao longo do contato com as encaixantes, onde a temperatura e mais baixa, que foram desmembradas, estiradas e rotacionadas durante o fluxo magmático. Nas fotos 2 e 4 são mostrados encraves com formas encurvadas e sigmoidais, respectivamente, que provavelmente assumiram essa morfologia porque sua orientaçáo inicial era oblíqua à da foliação magmática.

Discussão Do exposto acima conclui-se que a variação composicional nos granitos Pedra Lisa deve resultar de diferenciação por cristalização fracionada. $O$ fracionamento de minerais em magmas graníticos pode dar-se de várias maneiras, a mais comum sendo a segregação gravitacional. Porém. para o caso em análise, diferenciação por fluxo parece ser mais provável. Por esse mecanismo, um gradiente de velocidade causado pela fricçã́o e esfriamento ao longo dos contatos é estabelecido quando um magma se move por um conduto. Isso faz que partículas em suspensão migrem para o centro, onde a velocidade é maior. Esse efeito deve ser o responsável pela concentração de hornblenda em faixas quase monominerálicas, como ilustram as fotos 3 e 4, e o aumento de acidez de sul para norte é atribuído ao fracionamento desse mineral (e provavelmente também plagioclásio). $O$ aumento no volume de pegmatitos para o norte parece indicar que o magma origjnal era relativamente rico em água, pois mesmo fracionando uma fase hidratada foram atingidas condições de saturação em água, com a liberação de uma fase fluida; é possível, porém, que parte da água tenha sido assimilada das encaixantes.

As condições necessárias para a diferenciação por fluxo ser um processo efetivo são que os condutos atravessados pelo magma sejam estreitos e este contenha altas porcentagens de líquido (no mínimo 30\% em volume) (Barker 1983, p. 13233). Dadas as pequenas espessuras dos corpos graníticos, a primeira condição é plenamente satisfeita. Vernon (1986), baseado numa revisão da literatura, concluiu que feldspato potássico começa a precipitar em magmas graníticos, quando este ainda é de $60 \%$ a $70 \%$ líquido, e o desenvolvimento de fenocristais cessa, por falta de espaço, quando esse volume cai para $30 \%-40 \%$. Como fenocristais de feldspato potássico só não são abundantes nos membros mais diferenciados dos granitos Pedra Lisa, pode-se inferir que seu magma parental continha no máximo $30 \%$ (e provavelmente bem menos) de cristais em suspensão. A injeção de veios graníticos ao longo do bandamento dos migmatitos são claras evidências de que o magma era bastante móvel e, portanto, pouco cristalizado.

RELAÇÃO GRANITOGÊNESE DEFORMAÇÃO A presença de granitóides em zonas de cisalhamento tem sido documentada por vários autores (Blumenfeld \& Bouchez 1988, Castro 1986, Davies 1982a, 1982b, Guinebarteau et al. 1987, Hollister \& Crawford 1986). Geralmente, isso é atribuído à dilatação da crosta continental, com a abertura de fraturas que são preenchidas por magmas graníticos. Quando a deformação nessas zonas resulta de cisalhamento simples (sem componentes compressivos ou tensionais), as fraturas inicialmente formadas desenvolvem-se a $45^{\circ}$ da direção de cisalhamento, sendo progressivamente rotacionadas no decorrer da deformação. Claramente, este modelo não se aplica ao caso em análise porque a intrusão é subparalela aos limites da zona.

Tagliani \& Gomes (1988) reconheceram que a deformação na Zona de Cisalhamento Tauá é caracterizada por tectonitos $L$, sugerindo deformação em constrição (elipsóides prolatos, $k>1$ ). Isso e característico de zonas de cisalhamento transtensivas em que estruturas extensionais se iniciam em ângulos inferiores a $45^{\circ}$ (Sanderson \& Marchini 1984). Mesmo assim, este ângulo nâo é suficientemente reduzido para explicar a

geometria da intrusão. Por outro lado, a foliação interna à zona também é subparalela a seus limites, o que é devido ao fato de o ângulo entre a direção do cisalhamento e a foliação externa ser pequeno (Ramsay \& Huber 1983; ver Fig. 2). Em zonas de cisalhamento transcorrentes, a foliação é subverticalizada e, se ela se desenvolve em um regime transtensivo, a dilatação ocorre em uma direção normal às paredes' da zona, reduzindo a resistência oferecida à ascenção de magmas. Sugere-se, portanto, que a intrusão dos granitos Pedra Lisa se deu aproveitando os planos de foliação das encaixantes.

Uma comparação entre os dois mecanismos de intrusão discutidos acima e o processo clássico de diapirismo (March 1984. Pitcher 1979. Ramberg 1970) é apresentada na figura 3.

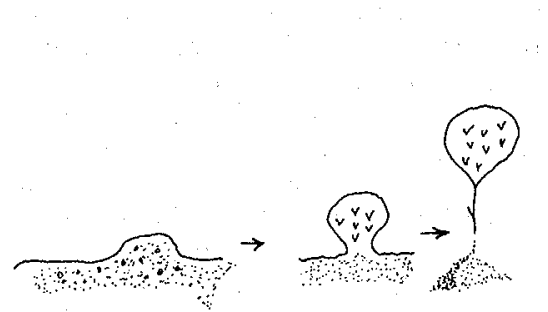

$(0)$

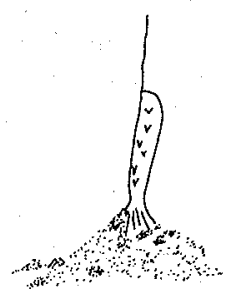

(c)

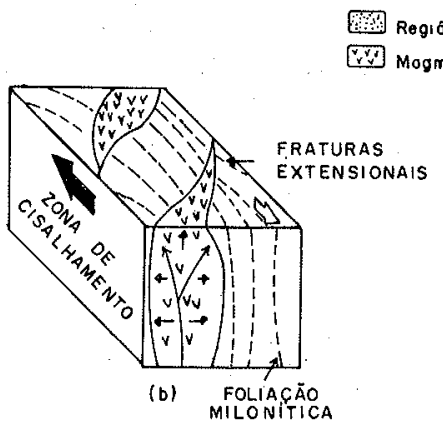

Figura 3 - Mecanismos de ascensâo de magmas graníticos pela crosta continental: a. por diapirismo; b. em fraturas extensionais em zonas de cisalhamento; c. ao longo dos planos de foliação em zonas de cisalhamento (simplificado e modificado de a. Ramberg 1970; b. Davies 1982b; c. Hollister \& Crawford 1986)

Figure 3 - Ascent models of granitic magmas through the continental crust: a. diapirism; b. through extension fractures in shear zones; $\mathbf{c}$. through the foliation planes in shear zones (simplified and modified from a. Ramberg 1970; b. Davies 1982b; c. Hollister \& Craw ford 1986)

Admitindo-se que a variação composicional encontrada de sul para norte resulta de cristalização fracionada, caso o fracionamento se tenha dado durante a ascensão do magma (ou seja, na vertical), seria necessário admitir-se uma das duas situações seguintes: a profundidade de intrusão se torna progressivamente menor para norte ou, alternativamente, a profundidade de geração do magma aumenta para o norte. A primeira hipótese pode ser descartada porque as paragêneses minerais das rochas regionais indicam as mesmas condições metamorficas por toda área em torno da zona de cisalhamento. A segunda hipótese é plausível porque, quanto maior fosse a distância vertical a ser percorrida pelo magma até o nível de intrusão, mais probabilidade ele teria de sofrer fracionamento. No entanto, é bem conhecido que líquidos não possuem resistência cisalhante (shear strength) e tendem a fluir quando submetidos a esforços cisalhantes. Por isso, e devido ao paralelismo entre a lineação mineral dadá pelos cristais de hornblenda nos granitos Pedra Lisa e a lineação de estiramento nas 
rochas encaixantes, considera-se mais provável que no nível de intrusão o movimento ascendente foi seguido por um transporte paralelo ao deslocamento das rochas encaixantes com o fracionamento se dando na horizontal.

$O$ modelo de ascensão e diferenciação proposto, ilustrado na figura 4, é o seguinte:

O magma deve ter começado a ascender na porção centrosul da área, atingindo um nível crustal em que o contraste de densidade e viscosidade com as encaixantes não permitiu mais sua subida. Caso a intrusão se tivesse dado em fraturas de extensão, à medida que novos pulsos magmáticos fossem chegando a esse nível, promoveriam um processo de baloneamento (por exemplo Castro 1986). Como ela se dá ao longo dos planos de foliação das encaixantes, porém, o deslocamento relativo dos blocos nos lados opostos da zona de cisalhamento fez o magma intrudido inicialmente se deslocar longitudinalmente, fracionando pelo mecanismo de diferenciação por fluxo, dando espaço assim para o continuado suprimento de magma. Algum fracionamento pode ter ocorrido durante a ascensão, mas, como os membros menos diferenciados são relativamente máficos e as evidências discutidas no item anterior indicam intrusão essencialmente no estado líquido, ela não deve ter sido de grande monta. Conseqüentemente, a temperatura do magma deveria ser relativamente elevada e sua viscosidade baixa, permitindo um deslocamento considerável antes de a cristalização ser completada.

A deformação na Zona de Cisalhamento Tauá teve início antes da injeção do magma granítico, como se viu anteriormente, e assim o movimento transcorrente deve ser independente da origem do magma. No entanto, o contraste de com- petência entre o granitóide e suas encaixantes deve ter promovido strain softening. Esse efeito pode ter sido ressaltado pela elevação de temperatura causada pela intrusão, produzindo uma concentração da deformação nas zonas de contato. Isso explica o fato de a região mais deformada estar disposta de forma aproximadamente simétrica em torno dos corpos graníticos (Fig. 2).

CONCLUSÃo Freqüentemente, dados litogeoquímicos e isotópicos são essenciais para se determinar, entre várias possibilidades, o mecanismo capaz de produzir variações composicionais em uma dada suíte de rochas ígneas. No entanto, nos últimos anos, uma revitalização dos estudos petrográficos e micropetrográficos contribuiu para que as feições observadas em granitóides fossem sujeitas a reinterpretações que, muitas vezes, conduziram à elaboração de novas teorias concernentes a sua origem e/ou cristalização. Também, como enfatizou Bateman (1985a, 1985b), um estudo integrado das estruturas presentes em corpos ígneos e em suas encaixantes é de grande importância para se determinar o mecanismo de intrusão.

Com base nessa visão, um modelo que explica a variação composicional nos granitos Pedra Lisa é proposto, em que: i. a ạscensão do magma é controlada pelos mergulhos subverticais das rochás regionais na Zona de Cisalhamento Tauá; ii. o deslocamento transcorrente dos blocos ao longo da zona induz um movimento horizontal do magma no nível de intrusão; iii. um mecanismo de diferenciação por fluxo é estabelecido e, à medida que os minerais cristalizados precocemente vão sendo segregados, o líquido remanescente se torna progressivamente mais ácido e mais rico em água.

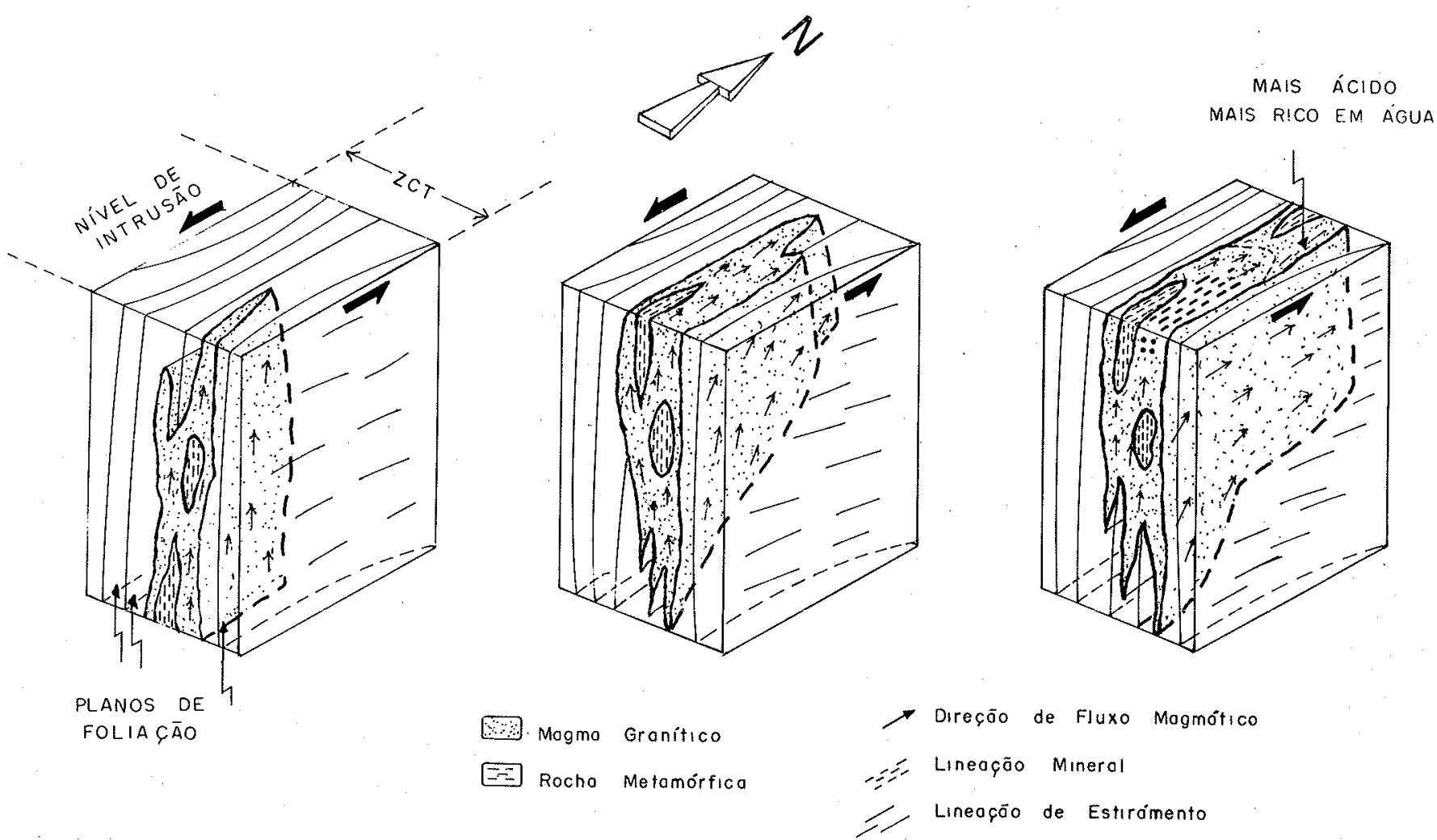

Figura 4 - Modelo de ascensão e diferenciação para o magma parental dos granitos Pedra Lisa: a. o magma começa a se deslocar em direção à superficie aproveitando a foliação subverticalizada na Zona de Cisalhamento Tauá; b. o movimento transcorrente da zona de cisalhamento começa a induzir um movimento horizontal ao magma; c. o movimento é dominantemente horizontal, o magma começa a cristalizar e um mecanismo de diferenciação por fluxo é estabelecido, promovendo o fracionamento dos cristais inicialmente formados de hornblenda

Figure 4 - Ascent and differentiation model to the parent magma of the Pedra Lisa granite: a. the magma begins its ascent towards the surface taking advantage of the subvertical foliation in the Taua shear zone; $b$. the transcurrent displacement in the shear zone begins to induce a horizontal flow to the magma at the intrusion level; $c$. the magmatic flow is dominantly horizontal, crystallization is advancing, and a mechanism of flow differentiation is stablished, promoting fractionation of the early formed hornblende crystals 
Agradecimentos As etapas de campo necessárias à direção deste trabalho foram realizadas enquanto o autor lecionava na Universidade de Fortaleza. Dessa forma, apresenta seus agradecimentos a todos os professores e alunos daquela insti- tuição, especialmente ao Professor Sívio Jorge Coelho Simões, com quem iniciou a pesquisa. Agradece ainda ao Professor Dr. Alcides N. Sial, pela revisão crítica do manuscrito.

\section{REFERÊNCIAS BIBLIOGRÁFICAS}

AGUE, J.J. BRIMHALL, G.H. 1987. Granites of the batholiths of California: products of local assimilation and regional-scale crustal contamination. Geology, 15:63-66.

ARTHAUD, M.H. 1986. A Falha de Tauá (CE): zona de cisalhamento dúctil de alto ângulo de rejeito múltiplo. In: CONGR. BRAS. GEOL., 34, Goiânia, 1986, Anais... Goiânia, SBG. v. 2, p. 766-769.

ARTHAUD, M.H.; HARTMANN, M.B ; TAGLIANI, T R M. 1988. Metamorfismo inverso na porção centro-oeste da Folha de Independência. Suas implicações estruturais e estratigráficas, Rev. Geologia (UFC), 1:41-44.

BARKER, D.S. 1983. Igneous rocks. New Jersey, Prentice-Hall, Inc. $417 \mathrm{p}$.

BATEMAN, R. 1985a. Aureole deformation by flattening around a diapir during in situ ballooning: the Cannibal Creek Granite. $J$. Geology, 93:293-310.

BATEMAN, R. 1985b. Progressive crystallization of a granitoid diapir and its relationship to stages of emplacement. J. Geology, 93:645-662.

BLUMENFELD, P. \& BOUCHEZ, J. 1988. Shear criteria in granite and migmatite deformed in the magmatic and solid states. $J$. Struct. Geol., 10:361-372.

BOWEN, N.L. 1928. The evolution of igneous rocks. New Jersey, Princeton University Press. 322p.

CASTRO, A. 1986. Structural pattern and ascent model in the Central Extremadura batholith, Hercynian belt, Spain, J. Struct. Geol., 8:633-645.

CHAPPELL, B.W.; WHITE; A.J.R.; WYBORN, D. 1987. The importance of residual source material (restite) in granite petrogenesis. J. Petrology; 28:1111-1138.

DAVIES, F.B. 1982a. Quantitative strain analysis of Pan-African granites intruded into a ductile shear zone in the Northwestern $A l$ Hijäz, Kingdom of Saudi Arabia. Deputy Ministry Resources, Saudi Arabia, PP-1, p. 51-66.

DAVIES, F.B. 1982b. Pan-African granite intrusion in response to tectonic volume changes in a ductile shear zone from Northern Saudi Arabia. J. Geology, 90:467-483.

DIDIER, J. 1973. Granites and their enclaves. Amsterdam, Elsevier, 393p.

DIDIER, J. 1987. Contribution of enclave studies to the understanding of origin and evolution of granitic magmas. Geol. Rundschau, 76:41-50.

EICHELBERGER, J.C. 1978. Andesitè volcanism and crustal evolution. Nature, 275:22-27.

FRY, N. 1979. Density distribution techniques and strained length methods for determination of finite strains. $\tilde{J}$. Struct. Geol., 1:221-229.

GOMES, J.R. de C.; GATTO, C.M.R.P.; SOUZA; G.M.C. de; LUZ, D.S. de; PIRES, J. de L.; TEIXEIRA, W. 1981. Projeto
Radambrasil. Folha SB. 24/25-Jaguaribe/Natal. Rio de Janeiro, $300 \mathrm{p}$.

GUINEBARTEAU, B.; BOUCHEZ, J.; VIGNERESSE, J, 1987. The Mortagne granite pluton (France) emplaced by pull-apart along a shear zone: structural and gravimetric arguments and regional implications. Geol. Soc. Am. Bull., 99:763-770.

HOLLISTER, L.S. \& CRAWFORD, M.L. 1986. Melt-enhanced deformation: a major tectonic process. Geology, 14:558-561.

MARCH, B.D. 1984. Reply to Comment on "On the mechanism of igneous diapirism, stoping and zone melting" by R. Bateman. Am. J.Sci., 284:981-984.

PITCHER, M.S. 1979. The nature, ascent, and emplacement of granitic magmas. J. Geol. Soc. London, 136:627-662.

RAMBERG, H. 1970. Model studies in relation to intrusion of plutonic bodies. In: NEWALL, G. \& RAST, N. ed. Mechanism of igneous intrusion. Geol. J. Spec. Issue, 2:261-286.

RAMSAY, J.G. \& HUBER, M.I. 1983. The techniques of Modern Structural Geology. Vol. 1: Strain analysis. London, Academic Press, 307p

REID, J.B., Jr.; EVANS, O.C.; FATES, D.G. 1983 Magma mixing in granitic rocks of the central Sierra Nevada, California. Earth Planet. Sci.Letters, 66:243-261.

SANDERSON, D.J. \& MARCHINI, W.R.D. 1984. Transpression. J. Struct. Geol., 6:449-458.

TAGLIANI, T.R.M. \& GOMES, J.R. de C. 1988. A deformação dos ortognaisses de Cratéus, CE. Rev. Geologia (UFC), 1:63-70.

TAGLIANI; T.R.M.; GOMES, J.R. de C.; ARTHAUD, M.B. 1988. A aplicação do método Fry nos ortognaisses de Cratéus, CE. Rev. Geologia (UFC), 1:57-62.

VERNON, R.H. 1983. Restites, xenoliths, and microgranitoid enclaves in granites. J. Proc. Roval Soc. N.S.M., 116:77-103

VERNON, R.H. 1986. K-feldspar megacrysts in granites-phenocrysts not porphyroblasts. Earth $S c i$. Rev., 22:1-63.

VERNON, R.H.; ETHERIDGE, M.A.; WALL, V.J. 1988. Shape and microstructure of microgranitoid enclaves: indicators of magma mingling and flow. Lithos, 22:3-12.

WALL, V.J.; CLEMENS, J.D.; CLARKE, D.B. 1987. Models for granitoid evolution and source compositions. J. Geology, 95:731-749

WHITE, A.J.R. \& CHAPPELL, B.W. 1977. Ultrametamorphism and granitoid genesis. Tectonophysics, 93:7-22.

ZORPI, M.J.; COULON, C.; ORSINI, J.B.; COCIRTA, C. 1989. Magma mingling, zoning, and emplacement in calc-alcaline granitoid plutons. Tectonophysics, 157:315-329.

MANUSCRITO 595

Recebido em 07 de marco de 1989

Revisão do autor em 16 de junho de 1989 Revisão aceita em 22 de junho de 1989

Penso que os geologos têm entendido que o registro geológico é constituído por um grande número de eventos que não são contínuos, eventos que sáo episódicos ou que podemos descrever como epiśdicos. Podemos considerar eventos epiśdicos como aqueles anuais ou regulares, ou ainda aqueles que acontecem muito comumente a períodos de 10 ou 100 anos que não sejam necessariamente regulares ou previsíveis. 